\title{
Augmented Reality Pengenalan Laboratorium FTKI Universitas Nasional dengan Tracking Based Navigation
}

\author{
Shofy Naqiyah ${ }^{\# 1}$, Septi Andryana ${ }^{\# 2}$, Ratih Titi Komalasari\#3 \\ \#Informatika, Fakultas Teknologi Komunikasi dan Informatika, Universitas Nasional \\ Jl. Sawo Manila, RT.14/RW.3, Ps. Minggu, Kec. Ps. Minggu, Kota Jakarta Selatan, Daerah Khusus Ibukota Jakarta \\ ${ }^{1}$ shofynaqiyah98@gmail.com \\ ${ }^{2}$ septi.andryana@civitas.unas.ac.id \\ 3ratih.titi@unas.civitas.ac.id
}

\begin{abstract}
Abstrak- Universitas Nasional merupakan salah satu universitas swasta di kota Jakarta yang memiliki beberapa fakultas, diantaranya Fakultas Teknologi Komunikasi dan Informatika. Pada fakultas tersebut terdapat empat laboratorium yang mendukung berjalan nya kegiatan belajar dan mengajar maupun kegiatan lainnya, tetapi masih banyak mahasiswa ataupun masyarakat umum yang belum mengetahui lokasi laboratorium tersebut. Penelitian ini menggunakan Augmented Reality dengan menerapkan tracking based navigation pada metode Markerless untuk mengarahkan user pada laboratorium. Hasil dari aplikasi ini menampilkan objek 3D dari area lab yang mengarahkan pengguna menuju lab yang ingin dikunjungi. Dengan adanya aplikasi Find Your Laboratory ini, pengguna dapat dengan mudah menemukan lokasi laboratorium yang ingin dituju. Hasil dari pengujian, didapat aplikasi berhasil di operasikan dengan jarak yang diuji minimal $10 \mathrm{~cm}$ sampai dengan jarak $1 \mathrm{~m}$ dari semua Android yang diujikan.
\end{abstract}

Kata kunci - Android, Objek 3D, Markerless, Laboratorium, Augmented Reality.

\section{Pendahuluan}

Universitas Nasional merupakan salah satu universitas swasta di kota Jakarta yang memiliki beberapa fakultas, diantaranya Fakultas Teknologi Komunikasi dan Informatika. Pada fakultas tersebut terdapat empat laboratorium yang mendukung berjalan nya kegiatan belajar dan mengajar. Laboratorium FTKI tidak hanya digunakan sebagai sarana perkuliahan, namun juga digunakan dalam kegiatan eksternal seperti workshop, sertifikasi, dan sosialisasi yang diadakan oleh himpunan atau fakultas lain. Beberapa mahasiswa mungkin sudah mengetahui dan familiar dengan lokasi Laboratorium FTKI, tetapi masih banyak mahasiswa ataupun masyarakat umum yang belum mengetahui lokasi laboratorium tersebut. Dengan demikian, di butuhkan alternatif navigasi yang dapat menunjukkan lokasi dari masing-masing laboratorium dengan bentuk 3D agar memudahkan pengguna menemukan tujuan mereka, sekaligus menjadi media pengenalan FTKI Universitas Nasional.

Pada penelitian terdahulu, dilakukan penelitian terkait navigasi dalam gedung yang menggunakan Augmented Reality dengan metode Markerless berupa denah gedung 3 lantai yang dibuat dalam bentuk 3D [1]. Pada penelitian lainnya, pemanfaatan metode Markerless juga digunakan dalam pengenalan kampus 1 Politeknik Harapan Bersama, dimana ditunjukkan informasi dari gedung yang dipilih dalam menu scan yang tampil pada AR kamera [2]. Pengenalan menggunakan Augmented Reality juga dilakukan untuk pemasaran perumahan pada PT. Alifa Citra Mulia. Ditunjukkan 2 buah model rumah dengan atap dan tanpa atap agar dapat melihat bagian dalam desain rumah tersebut yang dapat memudahkan pembeli dalam mempertimbangkan desain rumah yang telah disediakan [3].

Pengenalan dengan objek 3D yang menampilkan model desain rumah juga dilakukan pada penelitian katalog rumah di PT. Jashando Han Saputra [4]. Penelitian serupa juga dilakukan oleh Rhoza Prasetia dkk, dimana dalam penelitiannya memanfaatkan Markerless pada teknologi Augmented Reality untuk pengenalan Kampus Universitas Siliwangi yang menampilkan informasi dari masingmasing gedung dalam kampus tersebut [5]. Kemudian pada pengenalan kampus Universitas Wahid Hasyim Semarang juga dilakukan penelitian menggunakan Markerless Augmented Reality dengan menampilkan objek 3D kampus tersebut yang cukup besar dan luas [6].

Berdasarkan penelitian terdahulu penggunaan augmented reality dengan metode Markerless sudah banyak digunakan dan mendukung sarana informasi dengan baik. Maka penelitian kali ini, penulis menggunakan augmented reality dengan memanfaatkan metode Markerless Augmented Reality untuk pengenalan Laboratorium di lingkungan FTKI Universitas Nasional. 
Berdasarkan tujuan penelitian ini yang membahas tracking navigation menuju Laboratorium FTKI dan tidak membahas pada laboratorium dari fakultas lain, maka masalah pada penelitian ini dibatasi dari sisi tracking navigation yang dimulai dari lantai 4, dimana laboratorium FTKI berada, panah penunjuk jalan dimulai dari blok 4 dan blok 2 .

\section{Metode PEnelitian}

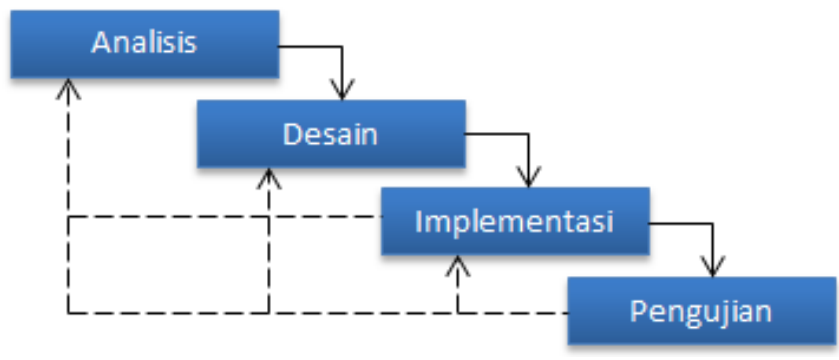

Gambar. 1 Metode SDLC

Tahapan metode penelitian yang digunakan pada penelitian ini yaitu Software Development Life Cycle (SDLC). Metode SDLC memiliki 4 tahapan penelitian yaitu analisis, desain, implementasi dan pengujian (Gambar 1).

1. Analisis

Proses pengumpulan data dalam menentukan kebutuhan perangkat lunak, pembuatan flowchart, spesifikasi aplikasi yang akan dibuat, software yang akan digunakan dalam membangun aplikasi.

2. Desain

Proses pembuatan desain interface, desain denah menuju area laboratorium, pembuatan storyboard, dan desain konsep aplikasi Find Your Laboratory.

3. Implementasi

Dari interface yang telah ada maka yang selanjutnya melakukan pembuatan objek 3D, pembuatan aplikasi AR untuk pengenalan laboratorium FTKI Universitas Nasional, membuat denah petunjuk menuju area laboratorium FTKI dan merekam suara untuk audio untuk mempermudah navigasi.

4. Pengujian

Proses pemeriksaan aplikasi yang telah dibuat dengan melakukan apakah menyelesaikan tujuan yang telah ditetapkan.

\section{A. Rancangan Aplikasi}

Pada Gambar 2 merupakan flowchart rancangan aplikasi dengan rincian tahapan sebagai berikut:

1. Mulai membuka aplikasi dimana muncul splash screen dan halaman Menu Utama, di dalamnya terdapat enam button, yaitu button Denah, button Laboratorium Network Data Communication, Laboratorium E-Commerce, Laboratorium Computer Vision and Multimedia, Laboratorium Artificial Intelligence dan button Exit.
2. Keempat Button Laboratorium saat di klik menampilkan AR Kamera, di dalamnya terdapat button start untuk memunculkan objek 3D lantai 4 Blok 4 dan sekitar selasar area laboratorium FTKI berada, yang mana juga ditunjukkan nama dari masing-masing laboratorium agar memudahkan pencarian pengguna. Selain itu, di dalam menu AR Kamera terdapat button rotate untuk memutar objek ke sisi yang lainnya dan button Back untuk kembali ke halaman utama. Pada menu tersebut juga terdapat suara yang menjelaskan tentang masing-masing laboratorium dan navigasi menuju lab tujuan.

3. Jika ingin menampilkan Denah, maka hanya perlu menekan button Denah, button ini menampilkan denah 2D yang mengarahkan pengguna dari gerbang unas menuju ke area laboratorium FTKI di lantai 4.

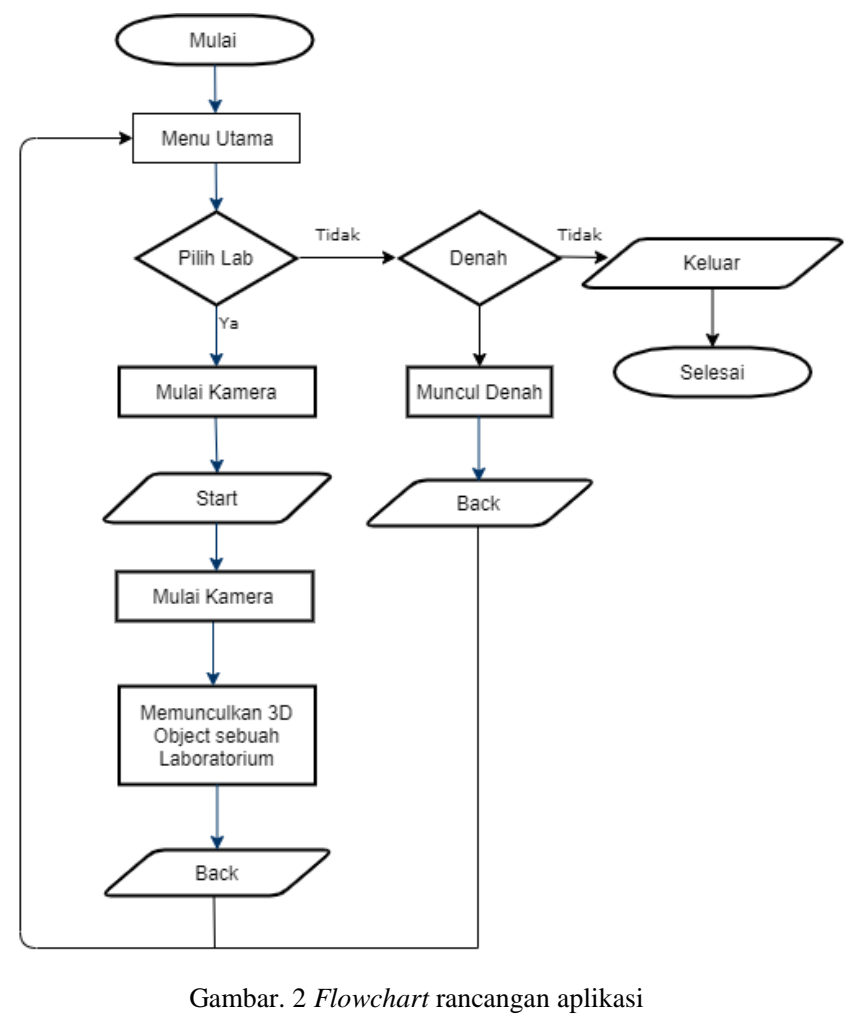

\section{B. Markerless Augmented Reality}

Augmented Reality adalah kombinasi antara dunia maya (virtual) dan dunia nyata (real) yang dibuat oleh komputer. Obyek virtual dapat berupa teks, animasi, model 3D atau video yang digabungkan dengan lingkungan sebenarnya sehingga pengguna merasakan objek virtual berada dilingkungannya[7][8]. Augmented Reality adalah cara baru dan menyenangkan dimana manusia berinteraksi dengan komputer, karena dapat membawa objek virtual ke lingkungan pengguna, memberikan pengalaman visualisasi yang alami dan menyenangkan[9].

Augmented Reality memiliki dua metode, yaitu Marker Based Tracking dan Markerless Augmented Reality. 
Marker Based Tracking menggunakan sebuah marker dalam aplikasinya untuk menampilkan objek yang dibuat[10][11], sedangkan Markerless merupakan metode Augmented Reality tanpa menggunakan frame marker sebagai objek yang dideteksi[12]. Dengan adanya Markerless Augmented Reality maka penggunaan marker akan digantikan dengan permukaan apapun yang berisi dengan tulisan, logo, atau gambar sebagai tracking object (obyek yang dilacak) agar dapat langsung melibatkan obyek yang dilacak tersebut sehingga dapat terlihat hidup dan interaktif, juga tidak lagi mengurangi efisiensi ruang dengan adanya marker[13][14].

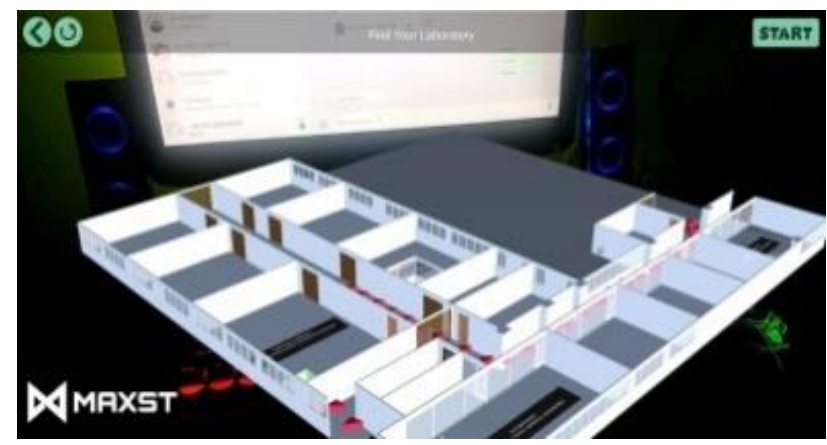

Gambar 3 Konsep Augmented Reality pada penelitian

Metode Markerless yang digunakan pada penelitian ini yaitu Tracking Based Navigation. Saat ini, sebagian besar sistem navigasi menggunakan sinyal satelit dari Global Positioning System (GPS), yang berfungsi di luar ruangan tetapi memiliki kesulitan di dalam ruangan karena berkurangnya sinyal. Di dalam ruangan sistem navigasi menjadi sangat berharga bagi beberapa penggunaan dan aplikasi[15][16].

Pada penelitian ini, lokasi yang dipilih untuk percobaan adalah Laboratorium FTKI Universitas Nasional (Gambar 3). Empat area berbeda setiap rute dipindai untuk mengembangkan peta lingkungan. Peneliti memunculkan denah laboratorium untuk mengarahkan pengguna menuju Laboratorium FTKI sehingga dapat membantu navigasi.

\section{HASIL DAN PEMBAHASAN}

\section{A. Analisa Kebutuhan Sistem}

Pada penelitian ini penulis menggunakan beberapa perangkat untuk membuat aplikasi AR, perangkat yang digunakan terdiri dari perangkat keras (hardware) dan perangkat lunak (software) yang dapat dilihat pada Tabel 1 dan Tabel 2.

TABEL I

SPESIFIKASI PERANGKAT KERAS

\begin{tabular}{|l|l|}
\hline \multicolumn{1}{|c|}{ Perangkat } & \multicolumn{1}{c|}{ Spesifikasi } \\
\hline Processor & AMD A4 3330MX \\
\hline Harddisk & $500 \mathrm{~GB}$ \\
\hline RAM & $8 \mathrm{~GB}$ \\
\hline
\end{tabular}

TABEL II

SPESIFIKASI PERANGKAT LUNAK

\begin{tabular}{|l|l|}
\hline \multicolumn{1}{|c|}{ Perangkat } & \multicolumn{1}{c|}{ Penggunaan } \\
\hline Unity 3D 2018.3.0f2 (64-bit) & Digunakan untuk membuat aplikasi AR \\
\hline Adobe Illustrator CC 2019 & $\begin{array}{l}\text { Digunakan untuk membuat desain } \\
\text { tampilan aplikasi }\end{array}$ \\
\hline Sweet Home 3D & $\begin{array}{l}\text { Digunakan untuk membuat arsitektur } \\
\text { 2D }\end{array}$ \\
\hline Draw.io & $\begin{array}{l}\text { Digunakan untuk menggambarkan } \\
\text { flowchart dari aplikasi yang dirancang }\end{array}$ \\
\hline
\end{tabular}

\section{B. Storyboard}

Dalam perancangan tampilan aplikasi, penulis membuat desain interface aplikasi yang ditunjukkan pada Tabel 3.

TABEL III

STORYBOARD APLIKAS

\begin{tabular}{|c|c|}
\hline Desain & Keterangan \\
\hline 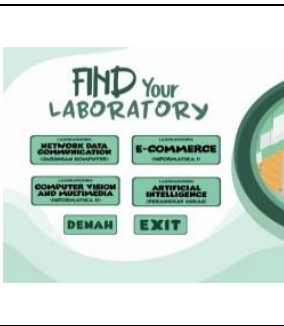 & $\begin{array}{l}\text { Tampilan Menu Utama yang } \\
\text { terdiri dari empat Button } \\
\text { Laboratorium (Lab.Network } \\
\text { Data Communication, } \\
\text { Lab.E-Commerce, } \\
\text { Lab.Computer Vision and } \\
\text { Multimedia, dan } \\
\text { Lab.Artificial Intelligence) } \\
\text { yang menampilkan menu } \\
\text { AR Kamera dan Button Exit. }\end{array}$ \\
\hline 80 & $\begin{array}{l}\text { Tampilan AR kamera pada } \\
\text { menu Laboratorium yang } \\
\text { terdiri dari button Back } \\
\text { untuk kembali ke Menu } \\
\text { utama, button rotate untuk } \\
\text { memutar objek dan button } \\
\text { Start untuk memulai objek } \\
\text { 3D. }\end{array}$ \\
\hline
\end{tabular}

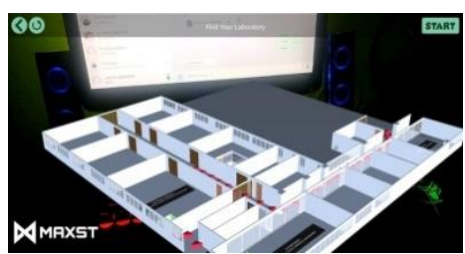

Tampilan AR kamera dengan objek 3D lantai 4 area. Laboratorium FTKI setelah button start di tekan.

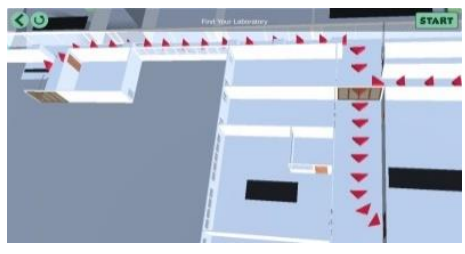

Tampilan AR kamera dengan objek 3D lantai 4 area laboratorium FTK dengan navigasi menuju Laboratorium Network Data Communication dari tangga blok 4 dan blok 2.

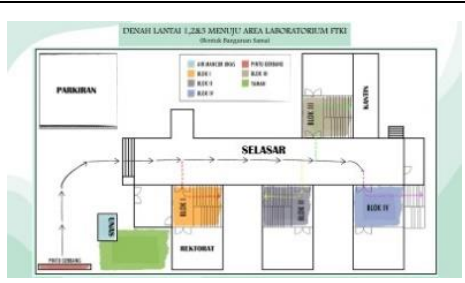

Tampilan menu Denah pada aplikasi yang menunjukkan denah 2D untuk mengarahkan pengguna dari pintu gerbang unas ke area laboratorium ftki. 


\section{Pengujian}

Pengujian dilakukan untuk mengetahui keberhasilan dari aplikasi yang dirancang. Pengujian terhadap intensitas cahaya dilakukan untuk mendapatkan kondisi terbaik dimana objek 3D tetap dapat muncul pada kamera AR, pengujian ditunjukkan pada Tabel 4.

TABEL IV

Pengujian Terhadap Intensitas CAhaya

\begin{tabular}{|c|c|c|c|}
\hline Android & Gelap & Redup & Bercahaya \\
\hline $\begin{array}{c}\text { Jelly Bean } \\
\text { (v4.2.2) }\end{array}$ & Tidak Muncul & Muncul & Muncul \\
\hline $\begin{array}{c}\text { Lollipop } \\
\text { (v5.0.0) }\end{array}$ & Tidak Muncul & Muncul & Muncul \\
\hline $\begin{array}{c}\text { Marshmallow } \\
\text { (v6.0.1) }\end{array}$ & Tidak Muncul & Muncul & Muncul \\
\hline $\begin{array}{c}\text { Nougat } \\
\text { (v7.0.1) }\end{array}$ & Tidak Muncul & Muncul & Muncul \\
\hline $\begin{array}{c}\text { Oreo } \\
\text { (v8.0.0) }\end{array}$ & Tidak Muncul & Muncul & Muncul \\
\hline $\begin{array}{c}\text { Pie } \\
\text { (v9.0.0) }\end{array}$ & Tidak Muncul & Muncul & Muncul \\
\hline
\end{tabular}

Pengujian pada Tabel 4 dilakukan terhadap versi Android yang diuji mengukur pada intensitas cahaya lingkungan, dari hasil pengujian didapatkan hasil bahwa objek 3D muncul pada kondisi redup dan bercahaya. Namun objek dan navigasi tidak akan muncul pada kondisi yang gelap.

Kemudian dilakukan pengujian pada jarak dengan tujuan untuk didapatkan jarak dimana objek 3D dapat terlihat pada kamera AR yang ditunjukkan pada Tabel 5 untuk semua Android yang diuji dapat menampilkan objek 3D.

TABEL V

PENGUJIAN TERHADAP DETEKSI JARAK

\begin{tabular}{|c|c|c|c|}
\hline \multirow{2}{*}{ Android } & \multicolumn{3}{|c|}{ Jarak Pengujian } \\
\cline { 2 - 4 } & $\mathbf{1 0} \mathbf{~ c m}$ & $\mathbf{1 0 0} \mathbf{c m}$ & $\mathbf{5 0 0} \mathbf{~ c m}$ \\
\hline $\begin{array}{c}\text { Jelly Bean } \\
\text { (v4.2.2) }\end{array}$ & Tidak Muncul & Muncul & Muncul \\
\hline $\begin{array}{c}\text { Lollipop } \\
\text { (v5.0.0) }\end{array}$ & Tidak Muncul & Muncul & Muncul \\
\hline $\begin{array}{c}\text { Marshmallow } \\
\text { (v6.0.1) }\end{array}$ & Tidak Muncul & Muncul & Muncul \\
\hline $\begin{array}{c}\text { Nougat } \\
\text { (v7.0.1) }\end{array}$ & Tidak Muncul & Muncul & Muncul \\
\hline $\begin{array}{c}\text { Oreo } \\
\text { (v8.0.0) }\end{array}$ & Tidak Muncul & Muncul & Muncul \\
\hline $\begin{array}{c}\text { Pie } \\
\text { (v9.0.0) }\end{array}$ & Tidak Muncul & Muncul & Muncul \\
\hline
\end{tabular}

Dilakukan dengan mendeteksi jarak kamera untuk dapat memunculkan objek 3D. Jarak pengukuran ditentukan dari jarak $10 \mathrm{~cm}$ sampai dengan $500 \mathrm{~cm}$ yang menghasilkan 3D objek tetap muncul.

Pengujian lain dilakukan secara langsung kepada beberapa mahasiswa FTKI dan fakultas lain dengan mengisi kuesioner setelah mengoperasikan aplikasi pada penelitian ini. Kuesioner dimaksudkan dengan tujuan mengetahui kesesuaian aplikasi yang dirancang terhadap respon pengguna setelah menggunakan aplikasi. Dari respon pengguna dilihat seberapa besar pengaruh dari penggunaan aplikasi terhadap user.

Total responden kuesioner sebanyak 12 mahasiswa Universitas Nasional. Kuesioner dilakukan menggunakan kuesioner yang berisikan 4 pertanyaan dengan hasil yang ditunjukkan pada Tabel 6.

TABEL VI

HASIL KUESIONER

\begin{tabular}{|l|l|c|}
\hline \multicolumn{1}{|c|}{ Aspek } & \multicolumn{1}{|c|}{ Indikator } & $\begin{array}{c}\text { Jawaban } \\
\text { Responden }\end{array}$ \\
\hline Pengetahuan akan lingkungan & - Baik & $71,4 \%$ \\
kampus Universitas Nasional & - Cukup & $28,6 \%$ \\
& - Kurang & - \\
\hline $\begin{array}{l}\text { Pengetahuan akan Fakultas } \\
\text { Teknologi Komunikasi dan }\end{array}$ & - Baik & $35,7 \%$ \\
Informatika & - Cukup & $57,1 \%$ \\
\hline \multirow{2}{*}{ Kesulitan menemukan laboratorium } & - Murang & $7,1 \%$ \\
FTKI & - Cukup & $57,1 \%$ \\
& - Sulit & $7,1 \%$ \\
\hline \multirow{2}{*}{ Efisiensi penggunaan aplikasi } & - Ya & $92,9 \%$ \\
& - Tidak & - \\
& - Mungkin & $7,1 \%$ \\
\hline
\end{tabular}

Berdasarkan data yang diberikan oleh responden melalui pengisian kuesioner, menunjukkan bahwa keberhasilan aplikasi yang dirancang dinilai berhasil dengan persentase $92,9 \%$ responden yang menyatakan bahwa penggunaan aplikasi dinilai efisien.

\section{KESIMPULAN}

Berdasarkan hasil penelitian, maka dapat disimpulkan bahwa:

1. Dari hasil rata - rata kuesioner, maka dapat disimpulkan aplikasi yang dirancang dapat dimanfaatkan untuk memandu informasi yang belum diketahui bagi mahasiswa baru, maupun pengunjung yang ingin datang ke laboratorium FTKI.

2. Aplikasi berhasil dioperasikan minimal pada versi Android Jelly Bean dalam keadaan yang bercahaya dan redup, sedangkan pada keadaan gelap objek tidak akan muncul.

3. Aplikasi berhasil di operasikan dengan jarak yang diuji minimal $10 \mathrm{~cm}$ sampai dengan jarak $1 \mathrm{~m}$ dari semua Android yang diujikan. 
4. Aplikasi dinilai berhasil dengan persentase efisiensi penggunaan aplikasi sebesar $92,9 \%$ dari total 12 responden.

\section{REFERENSI}

[1] P. O. Rotinsulu et al., "Implementasi Markerless Augmented Reality Untuk Navigasi Dalam Gedung," J. Tek. Elektro dan Komput., vol. 7, no. 3, pp. 323-330, 2018.

[2] I. Afriliana and J. Indriyanto, "IMPLEMENTASI AUGMENTED REALITY UNTUK PENGENALAN KAMPUS 1 POLITEKNIK HARAPAN BERSAMA," vol. 7, pp. 251-255, 2018.

[3] T. Hidayat, "Aplikasi Mobile Android untuk Pemasaran Perumahan Menggunakan Metode Markerless Augmented Reality pada PT . Alifa Citra Mulia," Apl. Mob. Android untuk Pemasar. Perumah. Menggunakan Metod. Markerless Augment. Real. pada PT. Alifa Citra Mulia, vol. 1, p. 8, 2015.

[4] Muntahanah, Rozali Toyib, and M. Ansyori, "Penerapan Teknologi Augmented Reality Pada Katalog Rumah Berbasis Android (Studi Kasus Pt. Jashando Han Saputra)," Pseudocode, vol. 1, no. 1, pp. 267-274, 2017.

[5] R. Prasetia, E. W. Hidayat, and R. N. Shofa, "Pengembangan Aplikasi Panduan Pengenalan Kampus Universitas Siliwangi Berbasis Augmented Reality Pada Perangkat Android," J. Tek. Inform. dan Sist. Inf., vol. 4, no. 3, pp. 478-487, 2018.

[6] S. Yudhistira, A. Riyantomo, and Mustagfirin, "Augemented Reality Media Pendukung... (Yudhistira dkk.)," pp. 140-145, 2015.

[7] D. Kurniawan, Aristoteles, and M. Fathan, "Implementasi Teknologi Markerless Augmented Reality Berbasis Android untuk Mendeteksi dan Mengetahui Lokasi SPBU Terdekat di Kota Bandar Lampung," J. Komputasi, vol. 3, no. 2, pp. 136-143, 2015.

[8] H. Setiawan, H. Mukhtar, and Soni, "Aplikasi Pengenalan Situs Bersejarah Di Kota Pekanbaru Dengan Augmented Reality Markerless Berbasis Android," J. FASILKOM, vol. 9, no. 2, pp. 387-395, 2019

[9] D. Hidayat and D. Irfan, "Rancang Bangun Aplikasi Denah Kampus Universitas Negeri Padang Menggunakan Augmented Reality Berbasis Android," J. Vokasional Tek. Elektron. dan Inform., vol. 6, no. 2, pp. 75-84, 2018.

[10] A. D. Rachmanto and M. S. Noval, "IMPLEMENTASI AUGMENTED REALITY SEBAGAI MEDIA PENGENALAN PROMOSI UNIVERSITAS NURTANIO BANDUNG MENGGUNAKAN UNITY 3D," vol. IX, no. 1, 2018.

[11] C. A. Oktavia, R. F. Setiawan, and A. Christianto, "Perancangan Aplikasi Augmented Reality Untuk Pengenalan Ruangan Menggunakan Marker 3D Objects Tracking," vol. 13, no. 1, pp. 53-60, 2019.

[12] H. F. Fat'hah Noor Prawita, "DiRoom Navigation: Sistem Navigasi di Dalam Toko Berbasis Realitas Tertambah," J. Chem. Inf. Model., vol. 4, no. 2, pp. 630-638, 2018.

[13] I. G. G. R. Wiradarma, I. G. M. Darmawiguna, and I. M. G. Sunarya, "Pengembangan Aplikasi Markerless Augmented Reality Balinese Story 'I Gede Basur,"' J. Nas. Pendidik. Tek. Inform., vol. 6, no. 1, p. 30, 2017.

[14] D. Abdullah, A. Sani, and A. Hasan, "Pemanfaatan Teknologi Augmented Reality Pada Media Pengenalan Bangunan Bersejarah Rumah Kediaman Bung Karno Bengkulu Berbasis Android," vol. V, no. September, pp. 21-29, 2018.

[15] G. Glass, U. Rehman, and S. Cao, "Augmented Reality-based Indoor Navigation : A Comparative Analysis of Handheld Devices vs .," vol. 47, pp. 140-151, 2017.

[16] M. Caferina and A. Sumarudin, "Augmented Reality Penunjuk Arah Jalan,” JTT (Jurnal Teknol. Ter., vol. 1, no. 1, 2018. 